\title{
A PERSPECTIVA BAKHTINIANA DAS ENUNCIAÇÕES EMERGENTES NA DITADURA MILITAR BRASILEIRA: REVISÃO DE LITERATURA
}

\author{
ENRICO DE CASTRO CARVALHO SILVA ${ }^{1}$
}

\author{
Pró-reitoria de Pesquisa e Pós-graduação (PRPPG) em Linguística Aplicada \\ Universidade de Taubaté (UNITAU) \\ Rua Visconde do Rio Branco, 210, Centro - Taubaté - SP - Brasil
}

enrico.carcavalho2012@gmail.com

\begin{abstract}
Resumo. O tema deste artigo é a revisão bibliográfica de pesquisas ligadas à abordagem bakhtiniana das enunciações emergentes no período da Ditadura Militar brasileira de 1964 a 1985. Como objetivo este artigo procura mostrar um recorte das análises que a pesquisa linguística brasileira, sob enfoque bakhtiniano, desenvolveu sobre as enunciações emergentes no contexto ditatorial. O pressuposto teórico desta pesquisa refere-se à concepção de linguagem desenvolvida por Bakhtin e seu Círculo. O método utilizado para a realização da pesquisa é a revisão de bibliografia, também denominado como "estado da arte". A análise dos dados evidenciou que há poucas pesquisas que articulam conceitos específicos do Círculo de Bakhtin e enunciações emergentes durante o autoritarismo da década de 1964. Conclui-se que a concepção bakhtiniana de linguagem pode contribuir para a compreensão mais apurada dos processos enunciativos durante a ditadura militar de 64.
\end{abstract}

Palavras-chave: dialogia; Ditadura Militar; poder político.

\begin{abstract}
The theme of this article is the bibliographic review of researches linked to the Bakhtinian approach to the enunciations emerging during the Brazilian Military Dictatorship period from 1964 to 1985. The objective of this article is to show an outline of the analyzes that Brazilian linguistic research, under a Bakhtinian approach, has developed on the emergent enunciations in the dictatorial context. The theoretical assumption of this research refers to the conception of language developed by Bakhtin and his Circle. The method used in this the research is the bibliography review, also known as "state of the art". The analysis of the data showed that there is little research that articulates specific concepts of the Bakhtin Circle and emergent enunciations during the authoritarianism of the 1964s. It is concluded that the baktinian conception of language can contribute to a more accurate understanding of the enunciative processes during the dictatorship military of 64 .
\end{abstract}

Keywords: dialogy; Military Dictatorship; political power.

\footnotetext{
${ }^{1}$ Mestrando em Linguística Aplicada pela Universidade de Taubaté (UNITAU).
} 


\section{INTRODUÇÃO}

Este artigo apresenta a revisão bibliográfica de pesquisas ligadas à concepção bakhtiniana de linguagem das enunciações emergentes no período da Ditadura Militar instaurada no Brasil de 1964 a 1985. Especificamente se busca compreender como as produções acadêmicas se caracterizam da perspectiva bakhtiniana do processo enunciativo dos atores políticos frente ao contexto de repressão promovida pelo Estado brasileiro.

Delinear o estado da arte das pesquisas brasileiras que articulam conceitos baktinianos ao contexto discursivo da Ditadura de Militar é fundamental para definir um ponto de partida para novas abordagens epistemológicas. Este trabalho objetiva mostrar um recorte das análises que a pesquisa linguística brasileira, sob enfoque bakhtiniano, desenvolveu sobre as enunciações emergentes no contexto ditatorial.

Esta é uma pesquisa do tipo estado da arte, caracterizada pela articulação de um levantamento bibliográfico que tem

[...] o desafio de mapear e de discutir uma certa produção acadêmica em diferentes campos do conhecimento, tentando responder que aspectos e dimensões vêm sendo destacados e privilegiados em diferentes épocas e lugares, de que formas e em que condições têm sido produzidas certas dissertações de mestrado, teses de doutorado, publicações em periódicos e comunicações em anais de congressos e de seminários. Também são reconhecidas [as pesquisas sobre estado da arte] por realizarem uma metodologia de caráter inventariante e descritivo da produção acadêmica e científica sobre o tema que busca investigar, à luz de categorias e facetas que se caracterizam enquanto tais em cada trabalho e no conjunto deles, sob os quais o fenômeno passa a ser analisado (FERREIRA, 2002, p. 258).

A seleção das produções indexadas no Portal de Periódicos da CAPES teve início com pesquisa dos termos específicos "discurso autoritário", "enunciação presidencial", "discurso ditatorial", sem nenhum resultado. Desse modo, houve necessidade de conferir uma amplitude aos termos, momento no qual a pesquisa "ditadura + bakhtin" apresentou 72 resultados (artigos).

Qualitativamente, após a leitura dos resumos, houve a constatação de que o viés das pesquisas pouco se relacionava com as enunciações dos atores políticos durante o período histórico da Ditadura Militar. Assim, a composição do corpus desta pesquisa contempla 8 artigos publicados no intervalo entre 2002 e 2019, que articulam conceitos essenciais desenvolvidos por Bakhtin e seu Círculo Discurso com enunciações emergentes na Ditadura Militar de 64.

A divisão deste artigo contempla duas seções: a perspectiva bakhtiniana e o contexto sócio histórico discursivo do Brasil no período da Ditadura Militar de 64; pesquisas que mobilizam categorizações bakhtinianas para análise de enunciações emergentes na Ditadura Militar de 64. 


\section{A PERSPECTIVA BAKHTINIANA E CONTEXTO SÓCIO-HISTÓRICO DISCURSIVO DO BRASIL NO PERÍODO DA DITADURA MILITAR DE 64}

A concepção bakhtiniana de linguagem se estrutura no dialogismo, assim os conceitos desenvolvidos são relacionais, indissociáveis e interdependentes. Diante dessa amplitude epistemológica, se faz necessária uma delimitação metodológica, portanto, esta seção trará uma articulação entre enunciação e ato responsável.

Considerando o objeto de estudo desta revisão de bibliografia, cumpre destacar o papel que enunciações emergentes durante o período da Ditadura Militar, instaurada no Brasil a partir de 1964, tiveram para comunicar as opressões do regime autoritário e mobilizar a luta para redemocratização.

A ótica bakhtiniana de linguagem sobre o conceito de enunciado concreto demanda um olhar de amplitude sobre a totalidade das obras de Bakhtin e seu Círculo, assim:

[...] mesmo dentro do pensamento bakhtiniano, as possibilidades de leitura dos termos enunciado, enunciado concreto e enunciação só têm sentido na articulação com outros termos, outras categorias, outras noções, outros conceitos que, mais do que a constitutiva proximidade, lhes conferem sentido específico, diferenciado de qualquer outra perspectiva teórica (BRAIT, 2018, p. 62).

Nota-se que está configurada uma oposição da concepção bakhtiniana de linguagem aos os conceitos linguísticos predecessores - em especialmente atrelados ao individualismo subjetivo do Romantismo (VOLÓCHINOV, 2018). Portanto, o desenvolvimento conceitual de enunciado concreto se amplia para além do texto, dotando-se de elementos essencialmente sociais para construção de significados. A enunciação articulada por um locutor ultrapassa suas percepções subjetivas individuais, mesmo antes de alcançar um interlocutor.

Todo enunciado, mesmo que seja escrito e finalizado, responde a algo e orienta-se para uma resposta. Ele é apenas um elo na cadeia ininterrupta de discursos verbais. Todo monumento continua a obra dos antecessores, polemiza com eles, espera por uma compreensão ativa e responsiva, antecipando-a etc. Todo monumento é uma parte real e indissolúvel ou da ciência ou da literatura ou da vida política (VOLÓCHINOV, 2018, p. 184).

Na medida em que a enunciação configura uma ação humana, ela é voltada para um "outro" vinculado a um contexto sócio histórico. Nesse sentido, a enunciação voltada à criação estética assimila elementos externos a uma consciência humana individualmente concebida. Para a concepção bakhtiniana de linguagem, a atividade estética é um ato responsivo e responsável:

Em seus primeiros ensaios, Arte e responsabilidade (1919) e Para uma filosofia do ato responsável (1920), Bakhtin já demonstra sua preocupação com o homem como ser pensante e responsável por seus atos, principalmente aqueles que dizem respeito à atividade estética. Tal 
preocupação acompanha suas reflexões posteriores a respeito da linguagem como meio de comunicação e fica bastante evidenciada, quando discorre sobre gêneros discursivos e suas características intrínsecas, entre elas a entonação e o tom valorativo. Essa peculiaridade do enunciado concreto também é discutida pelo Círculo [...] (PUZZO, 2017, p. 160).

Diante da proposta de pesquisa deste artigo fica claro que os enunciados concretos emergentes na ditadura militar de 1964 demandam uma articulação com o contexto sócio histórico em que seus locutores estavam inseridos. Além disso, tendo em vista a responsividade e responsabilidade atreladas ao ato enunciativo de criação estética é possível perceber uma tensão entre tons valorativos antagônicos: autoritarismo do Estado e resistência civil.

O tom valorativo dos enunciados concretos analisados por alguns estudos apresentados aqui reflete um comprometimento com uma postura estética e ética, na medida em que diante da concepção bakhtiniana de linguagem, o agir humano está vinculado ao impacto social posterior.

\begin{abstract}
A vida e a arte não devem só arcar com a responsabilidade mútua mas também com a culpa mútua. O poeta deve compreender que sua poesia tem culpa pela prosa trivial da vida e é bom que o homem da vida saiba que a sua falta de exigência e a falta de seriedade das suas questões vitais respondem pela esterilidade da arte. O indivíduo deve tornar-se inteiramente responsável: todos os seus momentos devem não só estar lado a lado na série temporal de sua vida mas também penetrar uns os outros na unidade da culpa e da responsabilidade (BAKHTIN, 2011, p. XXXIV).
\end{abstract}

Sob essa ótica é possível perceber que as enunciações artístico-literárias da Ditadura Militar de 1964 são alimentadas pelas diversas vozes que coexistiram no período. Desse modo, as análises dos estudos apresentados na seção posterior refletem e refratam uma realidade valorativa sócio histórica de responsabilização pelo agir ora vinculado às opressões promovidas pelo Estado, ora à luta pela redemocratização.

\title{
PESQUISAS QUE MOBILIZAM CATEGORIZAÇÕES BAKHTINIANAS PARA ANÁLISE DE ENUNCIAÇÕES EMERGENTES NA DITADURA MILITAR DE 64
}

Diante do breve levantamento conceitual apresentado, cabe relacionar os artigos publicados que trazem uma análise discursiva do período da Ditadura Militar de 64 sob perspectiva bakhtiniana. Nesse sentido, cronologicamente, têm-se:

Tabela 1. Compilação dos artigos analisados nesta pesquisa.

\begin{tabular}{|l|l|l|l|}
\hline $\mathrm{N}^{\mathrm{o}}$ & Publicação & Título & Autores \\
\hline 1 & $\begin{array}{l}\text { Alea, Rio de Janeiro, v. 11, n. 1, p. 148-165, jun. } \\
2009 .\end{array}$ & $\begin{array}{l}\text { Língua, discurso e } \\
\text { política }\end{array}$ & Fiorin \\
\hline 2 & $\begin{array}{l}\text { Estud. Lit. Bras. Contemp., Brasília, n. 43, p. } \\
111-132, \text { jun. 2014. }\end{array}$ & $\begin{array}{l}\text { Ditadura militar e } \\
\text { literatura } \\
\text { "parajornalística": }\end{array}$ & Schneider \\
\hline
\end{tabular}




\begin{tabular}{|c|c|c|c|}
\hline & & $\begin{array}{l}\text { desconstruindo } \\
\text { relações }\end{array}$ & \\
\hline 3 & $\begin{array}{l}\text { Bakhtiniana, Rev. Estud. Discurso, São Paulo, } \\
\text { v. } 10 \text {, n. 3, p. 5-26, dez. } 2015 .\end{array}$ & $\begin{array}{l}\text { Entre o semiótico e o } \\
\text { ideológico }^{2}\end{array}$ & Brait \\
\hline 4 & $\begin{array}{l}\text { Literatura e Autoritarismo, Santa Maria, n. 14, } \\
\text { p. } 62-68 \text {, fev. } 2015 .\end{array}$ & $\begin{array}{l}\text { Os motivos da } \\
\text { censura em feliz ano } \\
\text { novo, de Rubem } \\
\text { Fonseca }\end{array}$ & Garlet \\
\hline 5 & $\begin{array}{l}\text { Hist. cienc. saúde-Manguinhos, Rio de Janeiro, } \\
\text { v. } 22 \text {, n. } 3 \text {, p. } 723-741 \text {, set. } 2015 \text {. }\end{array}$ & $\begin{array}{l}\text { Fome, comida e } \\
\text { bebida na música } \\
\text { popular brasileira: } \\
\text { um breve ensaio }\end{array}$ & $\begin{array}{l}\text { Vasconcelos, } \\
\text { Vasconcelos e } \\
\text { Vasconcelos }\end{array}$ \\
\hline 6 & $\begin{array}{l}\text { Revista Labor, Fortaleza, v. 1, n. 17, p. 158-171, } \\
31 \text { jul. } 2017 .\end{array}$ & $\begin{array}{l}\text { Articulando discurso } \\
\text { com trabalho: } \\
\text { reflexões } \\
\text { bakhtinianas } \\
\text { vigotskianas da } \\
\text { canção "Construção" }\end{array}$ & $\begin{array}{l}\text { Aquino, Brito } \\
\text { e Colaço }\end{array}$ \\
\hline 7 & $\begin{array}{l}\text { Textos Escolhidos de Cultura e Arte Populares } \\
\text { (TECAP), Rio de Janeiro, v. 14, n. 1, p. 159- } \\
\text { 179, mai. } 2017 .\end{array}$ & $\begin{array}{l}\text { Chapa branca: farda e } \\
\text { fantasia nos desfiles } \\
\text { da Beija-Flor (1973 } \\
\text { 1975) }\end{array}$ & Silva \\
\hline 8 & $\begin{array}{l}\text { Alfa, rev. linguista. (São José Rio Preto), São } \\
\text { Paulo, v. } 63 \text {, n. } 2 \text {, p. } 243-263 \text {, set. de } 2019 .\end{array}$ & $\begin{array}{l}\text { Discursos } \quad \text { de } \\
\text { resistência: do } \\
\text { paratexto ao texto. } \\
\text { Ou vice-versa? }\end{array}$ & Brait \\
\hline
\end{tabular}

Fonte: Portal de Periódicos da CAPES

Fiorin (2009) estabelece como ponto de partida para sua pesquisa o desenvolvimento da polissemia da palavra "política", e adota um enfoque sobre a dinâmica de poderes nas relações sociais. Nesse sentido, apresenta os dois âmbitos que serão abordados em seu estudo sobre a relação entre poder e linguagem: "a) a natureza intrinsecamente política da linguagem e de suas manifestações, as línguas; b) as relações de poder entre os discursos e sua dimensão política" (FIORIN, 2009, p. 149).

Sobre a essência política da linguagem parte-se do pressuposto que a língua é um produto social da capacidade da linguagem. Nesse sentido, são expostas dinâmicas específicas quanto à lógica discursiva das línguas; algumas centram-se na oposição entre sujeitos e ações, objetos e propriedades, enquanto outras concebem a realidade como uma fusão de processos. Assim, a forma com que um falante vê o mundo é influenciada pelas categorizações características de determinada língua. Como exemplo apresentado:

[...] em português, chama-se posse a investidura, por exemplo, na Presidência da República; em inglês, inauguration; em francês, investiture. A palavra portuguesa dá ideia de assenhorear-se de alguma coisa, de domínio; a inglesa indica apenas começo; a francesa diz respeito ao recebimento da uma função. Esses termos têm, sem dúvida, relação com a maneira como concebemos o poder do Estado (FIORIN, 2009, p. 150).

\footnotetext{
${ }^{2}$ Cabe apontar que este artigo apresenta apenas uma referência direta à obra de Bakhtin e seu Círculo sobre a perspectiva semiótico-ideológica da linguagem - entretanto, dada a filiação teórica reconhecidamente bakhtiniana da pesquisadora e a relevância do desenvolvimento analítico enunciativo atrelado ao contexto da Ditadura Militar de 1964, a publicação foi mantida no corpus da presente pesquisa.
} 
Assim, é ressaltado que o desenvolvimento histórico da uma língua vincula os sujeitos que se utilizam dela para se comunicar a uma forma de organização do mundo.

A ordenação impositiva do mundo como consequência do poder é desenvolvida segundo a concepção barthesiana. Destaca-se que a imposição de uma ordem classificatória é vista como poder coercivo de opressão linguística, na medida em que a língua obriga o sujeito a ter sua dicção sobre o mundo de forma vinculada aos signos.

A respeito da dimensão política das relações de poder na linguagem, o ponto de partida é também é barthesiano. Nesse sentido, ressalta-se que a literatura é a forma linguística em que a língua escapa do poder.

Fiorin (2009) recorre à concepção bakhtiniana para explicar a relação do sujeito com a realidade e a relação entre poder e vozes sociais. $O$ autor ressalta que a realidade é apresentada aos sujeitos por meio dos processos de significação atrelados aos discursos do outro, esse intercâmbio discursivo é o dialogismo. Quanto à dinâmica entre as vozes sociais e poder, é pontuada a existência de forças centrípetas e centrífugas. As vozes que circulam estão vinculadas ao poder político na medida em que há uma regulação do dizer, as forças que fazem a manutenção da ordem discursiva são centrípetas, as centrífugas permitem uma descentralização.

As forças centrípetas têm um caráter essencialmente político e ideológico, pois intencionam exercer um controle semântico. Assim, restringindo a concepção de poder político ao poder exercido pelo Estado, a proibição do dizer - como preconiza Fiorin (2009) - imposta pela ditadura de 1964, configura o ânimo centralizador dos processos de significação.

O trabalho de Schneider (2014) é traçado sob o âmbito analítico do gênero discursivo romance-reportagem. Ao longo de seu estudo a autora apresenta um breve histórico sobre as motivações que levaram a crítica literária a desvalorizar as produções desse gênero:

[...] os pesquisadores da área de Letras viam, nos empreendimentos literários dos jornalistas, uma tentativa frustrada de denunciar a violência do regime. Em primeiro lugar, porque não aludiam diretamente à questão central da repressão. Sobre isso, Flora Süssekind (1984), por exemplo, afirma que o romance-reportagem funcionava como espécie de "compensação simbólica": o importante era restaurar a credibilidade do jornalista, dando ao leitor a sensação de estar lendo "verdades" ditas claramente, ainda que tais "verdades" não tivessem muita relevância no contexto político.

[...] Além disso, por ser mero complemento do "jornal censurado" ou da "televisão pasteurizada", ou seja, por não questionar a técnica e a retórica dos veículos de comunicação, que naturalizam cortes, simplificam relações e ocultam seleções arbitrárias, o romancereportagem não perturbava o leitor em sua maneira habitual de apreender o mundo pela linguagem, o que seria de se esperar de uma obra efetivamente revolucionária [...] (SCHNEIDER, 2014, p. 113, 114 e 115). 
Adiante é defendido que o gênero discursivo romance-reportagem tem um lugar de apreciação no contexto literário para além do período de violação da liberdade de imprensa. Nesse sentido, recorre-se à perspectiva bakhtiniana da construção do personagem. É posto que a criação verbal se contrapõe à experiência real, nessa o indivíduo reage responsivamente a um outro generalizado, naquela o narrador tem controle da consciência do personagem para construir sua identidade.

Portanto, Schneider (2014) conclui sobre o romance-reportagem que o processo de criação de personagens é um aspecto principal que consagra a relevância do gênero para a literatura. A experiência de leitura do gênero extrapola o retrato objetivo da realidade direcionando o leitor para um acompanhamento empático da trajetória do personagem.

O artigo de Brait (2015) que articula semiótica e ideologia revisita duas publicações de Fiorin (1988a, 1988b): Linguagem e Ideologia e O regime de 1964: discurso e ideologia. É evidenciado que as obras abordam a complexidade discursiva das enunciações presidenciais militares entre 1964 e 1978.

Além disso, para explicitar a relevância das obras, é feito um apontamento sobre a relação com a perspectiva bakhtiniana de linguagem:

[...] minha pesquisa também se caracteriza pela tentativa de relacionar, muito frequentemente, língua, linguística, literatura e, nessa intersecção, voltar o olhar para uma concepção semiótico-ideológica de linguagem da que reconheço a importância dessas obras do autor. [...] A perspectiva semiótico-ideológica é uma marca da concepção de linguagem desenvolvida por M. Bakhtin e o Círculo, especialmente V. Volochínov e P. Medviédev, já no início dos anos 1920, sendo essa minha filiação teórica de base (BRAIT, 2015, p. 8).

A abordagem principal do estudo é a configuração da linguagem como veículo ideológico. O processo de significação dos discursos está atrelado aos valores ideológicos que descortinam diversas visões de mundo.

É nesse sentido que Brait (2015) retoma O regime de 1964: discurso e ideologia, evidenciando que os discursos oficiais do Estado emergentes durante o golpe de 64 têm um direcionamento semântico instaurado pelo poder militar. O processo de significação imposto pelo discurso consiste em validar a parte da realidade, ou sua refração, como a totalidade.

O discurso do poder de 1964 é caracterizado como permeado pela ideologia de dominação:

Por meio de um jogo minucioso, a análise vai desvendando o discurso do poder de 1964, incluindo a ideologia da dominação, a ordem e o caos, a subversão, a legalidade "revolucionária", a narrativa conservadora que define o discurso do movimento militar, a caracterização dos oponentes como traidores da pátria, as realizações desse movimento como contenção dos movimentos sociais, a guerra contra o comunismo (BRAIT, 2015, p. 22). 
O direcionamento semântico do movimento militar como revolucionário pautado na transformação social - é estruturante do discurso que fundamenta uma percepção de realidade atrelada à ideologia dominante que pretendia fazer a manutenção dos valores.

O estudo é finalizado com uma aproximação entre o discurso político e o discurso religioso por meio de um processo denominado sacralização. Diante dele há um deslocamento de características ligadas a Deus para o Estado, consolidando um controle sobre o povo.

Garlet (2015) apresenta um estudo sobre processo de censura ao enunciado concreto Feliz Ano Novo, escrito por Rubem Fonseca, durante o período da Ditadura Militar em 1975. Sua análise é estruturada na concepção bakhtiniana de linguagem, especificamente no conceito de ideologia preconizado por Medviédev (2012).

É exposto que o conto de Rubem Fonseca consolida uma narrativa descritiva e minuciosa da violência com a intenção de estruturar uma banalização, de caracterizar a ausência de estranhamento. Contudo, a essa postura estética é posta como uma crítica à violência, autoritarismo e censura legitimados pela doutrina de Segurança Nacional.

A visão bakhtiniana de linguagem é referenciada para articular a ideologia como elemento mediador da existência humana. Assim, tendo em vista que o meio ideológico é constituído por uma diversidade simbólica que se significa diante de valores correntes na sociedade é feita uma caracterização do contexto ideológico de emergência do conto de Rubem Fonseca:

O meio ideológico no qual Rubem Fonseca está imerso ao criar Feliz Ano Novo é a Ditadura Civil-Militar (1964-1985), caracterizada pelo autoritarismo, pela violência e pela censura, orientadas pela Doutrina de Segurança Nacional, a qual prevê o combate aos supostos subversivos como uma meta imprescindível, conforme podemos ler em Comblin (1978). De acordo com a Doutrina, todas as medidas arbitrárias eram necessárias para o combate ao perigo comunista, avalizando, então, sob a ótica governamental, a tortura e a censura, e criando - especialmente após o Ato Institucional $\mathrm{n}^{\circ}$ 5, de 1968 - uma "cultura do medo", segundo Alves (1985), na qual todos eram potenciais subversivos (GARLET, 2015, p. 64).

Dessa forma, o aspecto principal apontado por Garlet (2015) que motivou a censura do enunciado concreto foi o entendimento superficial que os censores tiveram de que a narrativa estimula o atendado à ordem pública, em contrapartida à intenção do escritor de denunciar a desumanização do regime político da época.

O gênero musical canção-protesto é analisado por Vasconcelos, Vasconcelos e Vasconcelos (2015) frente à perspectiva bakhtiniana de signo ideológico e palavra, levando em conta o contexto econômico, político e social da Ditadura Militar (1964 1985).

O desenvolvimento conceitual do termo ideologia se refere ao processo, essencialmente social, de atribuição de significado à palavra, ou signo ideológico. Nesse 
contexto, os signos ideológicos abordados no artigo estão atrelados à construção da identidade brasileira baseada no consumo de determinados alimentos durante período ditatorial a partir de 1964. A identidade é definida pelo significado simbólico do consumo do feijão e da coca-cola e também pelo contexto social da fome:

Recordamos que, à época, as contradições do período de milagre econômico brasileiro (1968-1974), tais como a elevação das taxas de desemprego, o arrocho salarial, o aumento da inflação, a concentração da renda e da terra, as elevadas taxas de mortalidade infantil, de doenças infecciosas e parasitárias, de fome, de desnutrição, de deficit de crescimento e outras deficiências nutricionais, foram amplamente divulgadas na imprensa nacional e internacional, mesmo com a criteriosa censura nos meios de comunicação (VASCONCELOS, VASCONCELOS e VASCONCELOS, 2015, p. 727 e 728).

Diante disso, é destacado que o processo de significação dos signos ideológicos, inseridos nas canções-protesto, tinham "o papel de retratar cenas do contexto histórico, denunciando as condições de fome, miséria, violência e exploração de significativas parcelas da população brasileira" (VASCONCELOS, VASCONCELOS e VASCONCELOS, 2015, p. 736). Portanto, os signos ideológicos refletem e refratam uma realidade sociocultural de resistência civil ao regime militar, por parte dos locutores e interlocutores.

Aquino, Brito e Colaço (2017) promovem um estudo sobre a enunciação Construção, canção lançada por Chico Buarque em 1971, levando em conta o enfoque bakhtiniano. A pesquisa recorre ao dialogismo para explicar o diálogo interior e exterior do locutor com a sociedade para trazer significado ao trabalho:

A concepção dialógica de Bakhtin pode colaborar na compreensão do processo de desenvolvimento da atividade laboral e de seus impedimentos visto que a noção de humanização se dá através do trabalho enquanto atividade mediada e mediatizante (AQUINO, BRITO e COLAÇO, 2017, p. 162)

Na medida em que o trabalho é significado como atividade mediadora da condição humana e que as enunciações emergentes nas interações laborais traduzem ideologias correntes, a compreensão dos significados gerados é determinante para a inserção do indivíduo em determinado grupo social.

Nesse sentido, é evidenciada a significação, considerada subversiva pelo regime militar, gerada pela enunciação de Chico Buarque, na medida em que o retrato da realidade de exploração possibilita a conscientização do trabalhador sobre a marginalização.

O texto sugere um processo de repetição em relação às ações executadas na vida e no trabalho de um operário do segmento de construção, denunciando uma mecanização do corpo e da vida.

O sujeito operário é oculto enfatizando sua despersonalização, o que ocorre também com os outros personagens como a mulher que pode ser a última ou a única e os filhos que podem ser o único ou o pródigo. 
Representando qualquer operário da construção (AQUINO, BRITO e COLAÇO, 2017, p. 165)

Assim, tendo em vista que a perspectiva bakhtiniana sobre consciência é vinculada às relações sociais, Construção é uma enunciação que mobiliza um discurso ideológico frente à consciência de classe dos trabalhadores.

O artigo de Silva (2017) se propõe a analisar as enunciações referentes aos enredos da GRES Beija-Flor conhecidos entre os anos de 1973 a 1975 quanto à articulação ideológica com o discurso do regime militar brasileiro. O principal conceito da concepção bakhtiniana de linguagem usado como fundamentação é a carnavalização.

Encontramos na literatura de Bakhtin, o cerne da cultura cômica popular, um grande repertório no qual o autor se aprofunda em questões das festas populares durante a Idade Média e o Renascimento e seu emblema principal - o carnaval.

Segundo o autor, o carnaval tinha papel central na sociedade medieval, com as festas carnavalizadas do período, que aparecem em outras festividades, entre as religiosas, de aspecto mais cômico e popular, sendo o público tratado, ainda, como a criação de um segundo mundo. Essa dualidade estaria relacionada diretamente às questões do Estado feudal e da Igreja, como toda a hierarquia e a religiosidade feudais impostas, e o rebaixamento e destronamento das verdades e certezas da esfera oficial da sociedade. Bakhtin encontrou duas palavras para sintetizar sua análise diante a cultura cômica popular - o universalismo e a liberdade. As festividades populares e o carnaval trazem ao nosso entendimento uma relação intrínseca do oficial à existência humana para confirmar a ordem social do período, pois, embora existam questões hierárquicas determinantes para a sociedade, as festividades tinham por finalidade a consagração do rompimento com as hierarquias. (SILVA, 2017, p. 167 e 168).

Diante dessa articulação conceitual o estudo chama atenção para a ambiguidade do carnaval, na medida em que coexistiu uma exaltação do regime militar em uma festa popular que essencialmente destrona verdades impostas pela ideologia dominante.

É ressaltado que desde o golpe de 1964, "cujo caráter repressivo se amplia a partir de 1968, as escolas de samba cariocas sentiram a repercussão de seu poder, sobretudo na década de 1970, com a propaganda do milagre brasileiro" (SILVA, 2017, p. 176). Assim, fica evidente que o domínio que o Estado militarizado exercia sobre as instituições ligavase intimamente ao discurso.

A pesquisa de Brait (2019) promove uma discussão sobre os discursos de resistência frente à ditadura militar brasileira no período compreendido entre 1960 e 1980 . Sendo a autora uma estudiosa das ideias de Bakhtin e seu Círculo, este estudo está permeado por diversos conceitos bakhtinianos, mas cabe destacar a constituição discursiva por meio dos gêneros.

Dentre esses discursos, que se constituem por meio de diferentes gêneros, com circulação em diferentes esferas, o literário será tomado aqui como aquele que mantém "relação de reciprocidade e interdependência entre os diversos campos da cultura" (BAKHTIN, 
2017, p. 11-12) e "se revela, antes de tudo na unidade diferenciada da cultura da época de sua criação" (BAKHTIN, 2017, p. 16).

Isso significa que, por meio do discurso literário de resistência, algumas particularidades da cultura brasileira de ao menos dois momentos estarão em jogo, em tensão, tocando-se no limiar, nas fronteiras temporais, espaciais, sociais, afetivas. Ou seja, dimensões que sofreram a intervenção da ditadura, sendo por ela afetadas, se defrontam com documentos e discursos atuais que enfrentam e confrontam o doloroso passado. Juntando-se a isso o fato de que os gêneros, artísticos ou não, "acumulam formas de visão e assimilação de determinados aspectos do mundo" (BAKHTIN, 2017, p. 16), a enunciação da resistência, o enunciado concreto que a sustenta e concretiza, e que inclui necessariamente o objeto que a propulsiona (no caso os desmandos fatais, alucinados e inverossímeis dos tempos da ditadura), debate-se entre ao menos dois polos em intersecção, em tensa interação (BRAIT, 2019 , p. 244 e 245).

Nesse contexto, é destacado como gênero discursivo a prosa de resistência, constituída por enunciações que orbitam entre o real e a ficção, entre o presente e o passado. O locutor deste gênero vivencia uma realidade sócio histórica e afetiva permeada por "culpa e a insegurança discursiva dos que, tendo sobrevivido, assumem o dever de enunciar, na tentativa de presentificar a ausência dos mortos e os horrores do regime" (BRAIT, 2019, p. 245). Nesse âmbito, a resistência é ao discurso oficial de negação das violações à dignidade humana promovidas pelo Estado de exceção.

Através da análise de enunciados concretos, Brait (2019) evidencia o heterodiscurso:

Considerando que o discurso de resistência está sendo caracterizado, dentre outros aspectos, pela capacidade de mobilizar vozes sociais, também os paratextos serão observados sob esse ângulo, ou seja, enquanto heterodiscursos. Cada um por si e também em conjunto, eles enunciam, põem em movimento, discursos de resistência, no sentido de delinear o alvo a quem o enunciador vai se contrapor, o objeto da resistência, estabelecendo, ao mesmo tempo, uma parceria com o leitor. Trata-se de um diálogo velado, que qualifica o leitor como capaz de, antecipadamente, compreender importantes faces que motivam e sustentam o discurso que ele terá pela frente (BRAIT, 2019, p. 253).

Os discursos literários de resistência analisados têm seu dialogismo fundado na retomada histórica de vozes por meio de paratextos (dedicatórias, epígrafes, prefácio, posfácio etc.) que emolduram o texto principal. Há, portanto, camadas enunciativas que medeiam gradativamente a percepção do interlocutor do discurso de resistência, fazendo com que ele se dilua na memória coletiva marcada pela opressão ditatorial.

Frente aos estudos apresentados, fica evidente que a presença de categorizações bakhtinianas no corpus de pesquisa analisado apresenta duas acepções: concepção de linguagem e caracterização de enunciados concretos.

A intersecção entre língua, linguística e literatura (BRAIT, 2015) é característica da concepção bakhtiniana de linguagem. Dessa forma, as análises do contexto sócio discursivo da ditadura de 1964 que desenvolveram essa amplitude foram sinalizadas. 
Quanto à análise de enunciados concretos emergentes na ditadura de 1964, os estudos que recorreram, especificamente, a conceitos bakhtinianos para promover uma caracterização do processo discursivo também foram sinalizados. Portanto, o quadro a seguir compila esses dados.

\section{Quadro 2. Corpus de análise e respectivo referencial teórico dos artigos compilados}

\begin{tabular}{|l|l|l|l|l|}
\hline $\mathrm{N}^{\circ}$ & Corpus de Análise & $\begin{array}{l}\text { Concepção de } \\
\text { linguagem sob o } \\
\text { âmbito } \\
\text { bakhtiniano }\end{array}$ & $\begin{array}{l}\text { Caracterização } \\
\text { de enunciados } \\
\text { concretos sob o } \\
\text { âmbito } \\
\text { bakhtiniano }\end{array}$ & Ambos \\
\hline 1 & $\begin{array}{l}\text { Abordagens para a questão das } \\
\text { relaçães entre língua, discurso e } \\
\text { política }\end{array}$ & $\mathrm{X}$ & & \\
\hline 2 & $\begin{array}{l}\text { Abordagem do romance-reportagem } \\
\text { brasileiro da década de 1970 pela } \\
\text { crítica literária acadêmica }\end{array}$ & $\mathrm{X}$ & $\mathrm{X}$ & $\mathrm{X}$ \\
\hline 3 & $\begin{array}{l}\text { Articulação existente entre semiótica } \\
\text { e ideologia como marca original e } \\
\text { fundante do pensamento do linguista } \\
\text { brasileiro José Luiz Fiorin }\end{array}$ & $\mathrm{X}$ & $\mathrm{X}$ & \\
\hline 4 & $\begin{array}{l}\text { Análise do conto Feliz Ano Novo, de } \\
\text { Rubem Fonseca }\end{array}$ & $\mathrm{X}$ & $\mathrm{X}$ & $\mathrm{X}$ \\
\hline 5 & $\begin{array}{l}\text { Análise de canção de protesto (1964- } \\
1985)\end{array}$ & $\mathrm{X}$ & $\mathrm{X}$ & $\mathrm{X}$ \\
\hline 6 & $\begin{array}{l}\text { Discussão sobre as categorias } \\
\text { discurso e trabalho através da canção } \\
\text { "Construção" de Chico Buarque }\end{array}$ & $\mathrm{X}$ & $\mathrm{X}$ & $\mathrm{X}$ \\
\hline 7 & $\begin{array}{l}\text { Estudo sistemático dos enredos } \\
\text { chapa branca no GRES Beija-Flor de } \\
1973 \text { a 1975 }\end{array}$ & $\mathrm{X}$ & $\mathrm{X}$ & $\mathrm{X}$ \\
\hline 8 & $\begin{array}{l}\text { Discussão das estratégias de } \\
\text { discursos de resistência à ditadura } \\
\text { militar brasileira de 1960 a 1980 }\end{array}$ & $\mathrm{X}$ & $\mathrm{X}$ & \\
\hline
\end{tabular}

Os artigos selecionados refletem a polifonia característica do universo bakhtiniano, que é "bastante amplo, pois os interlocutores que integram o Círculo são de áreas muito distintas [e] o resultado desse diálogo extrapola os limites da simples discussão linguística" (PUZZO, 2017, p. 160).

Além disso, as pesquisas analisadas evidenciam que os conceitos desenvolvidos por Bakhtin e o Círculo integram um universo essencialmente dialógico em constante (re)construção, portanto cada categorização tem sua significação desenvolvida diante da unidade arquitetônica do pensamento do Círculo. 


\section{CONSIDERAÇÕES FINAIS}

Todos os artigos analisados mobilizam categorizações bakhtinianas na apreensão do corpus de pesquisa ambientado no contexto sócio histórico discursivo da ditadura militar, instaurada no Brasil a partir de 1964.

Contudo, diante de um recorte mais apurado, referente ao desenvolvimento de conceitos específicos da concepção bakhtiniana de linguagem para analisar enunciados concretos emergentes nesse mesmo contexto sócio histórico, há um novo agrupamento equivalente a $75 \%$ das pesquisas realizadas (última coluna do quadro 2 ).

Considerando a fecundidade do pensamento de Bakhtin e seu Círculo sobre linguagem, há um caminho considerável a ser percorrido pela pesquisa quanto às análises discursivas de enunciações emergentes em períodos de autoritarismo do Estado, em especial sob o âmbito dos conceitos de ideologia e ato responsivo e responsável.

\section{REFERÊNCIAS}

BAKHTIN, Mikhail. Estética da criação verbal. $6^{\text {a }}$ ed. Trad. Paulo Bezerra. São Paulo: Editora WMF Martins Fontes, 2011.

BRAIT, Beth. Discursos de resistência: do paratexto ao texto. Ou vice-versa?. Alfa, rev. linguista. (São José Rio Preto), São Paulo, v. 63, n. 2, p. 243-263, set. de 2019. Disponível em <http://www.scielo.br/scielo.php?script=sci_arttext\&pid=S1981$57942019000200243 \& \operatorname{lng}=$ en\&nrm $=$ iso $>$.

BRAIT, Beth. Entre o semiótico e o ideológico. Bakhtiniana, Rev. Estud. Discurso, São Paulo, v. 10, n. 3, p. 5-26, dez. 2015. Disponível em http://www.scielo.br/scielo.php?script=sci_arttext\&pid=S2176-

45732015000300005\&lng=en\&nrm=iso. Acesso em: 27 jul. 2020.

BRAIT, Beth e MELO, Rosineide de. Enunciado/enunciado concreto/enunciação. In: BRAIT, Beth. Bakhtin: conceitos-chave. 2a ed. São Paulo: Contexto, 2018, p.61-78.

COLAÇO, Veriana de Fátima Rodrigues; DE AQUINO, Cássio Adriano Braz; DE BRITO, Mariana Aguiar Alcântara. Articulando discurso com trabalho: reflexões bakhtinianas e vigotskianas da canção "construção". Revista Labor, Fortaleza, v. 1, n. 17, p. 158-171, 31 jul. 2017. Disponível em: http://www.periodicos.ufc.br/labor/article/view/18911/30600. Acesso em: 27 jul. 2020.

DA SILVA, Carlos Carvalho. Chapa branca: farda e fantasia nos desfiles da Beija-Flor (1973 1975). Textos Escolhidos de Cultura e Arte Populares (TECAP), Rio de Janeiro, v. 14, n. 1, p. 159-179, mai. 2017. Disponível em: https://www.epublicacoes.uerj.br/index.php/tecap/article/view/30784. Acesso em: 27 jul. 2020.

FIORIN, José Luiz. Língua, discurso e política. Alea, Rio de Janeiro, v. 11, n. 1, p. 148165, jun. 2009. Disponível em: http://www.scielo.br/scielo.php?script=sci_arttext\&pid=S1517106X2009000100012\&lng=en\&nrm=iso. Acesso em: 27 jul. 2020.

GARLET, Deivis Jhones. Os motivos da censura em Feliz Ano Novo, de Rubem Fonseca. Literatura e Autoritarismo, Santa Maria, n. 14, p. 62-68, fev. 2015. Disponível em: https://periodicos.ufsm.br/LA/article/view/18513/10911. Acesso em: 27 jul. 2020. 
PUZZO, Miriam Bauab. Romance inconcluso em diversos olhares ou perspectivas. In: KOZMA, Eliana Viana Brito e PUZZO, Miriam Bauab. Mútiplas linguagens: discurso e Efeito de sentido. Campinas: Pontes Editores, 2017, p.155-179.

SCHNEIDER, Sabrina. Ditadura militar e literatura "parajornalística": desconstruindo relações. Estud. Lit. Bras. Contemp., Brasília, n. 43, p. 111-132, jun. 2014. Disponível em: $\quad$ http://www.scielo.br/scielo.php?script=sci_arttext\&pid=S231640182014000100007\&lng=en\&nrm=iso. Acesso em: 27 jul. 2020.

VASCONCELOS, Francisco de Assis Guedes de; VASCONCELOS, Mariana Perrelli; VASCONCELOS, Iris Helena Guedes de. Fome, comida e bebida na música popular brasileira: um breve ensaio. Hist. cienc. saude-Manguinhos, Rio de Janeiro, v. 22, n. 3, p. 723-741, $\quad$ set. 2015.20 Disponível em: $\quad$ http://www.scielo.br/scielo.php?script=sci_arttext\&pid=S010459702015000300723\&lng=en\&nrm=iso. Acesso em: 27 jul. 2020.

VOLÓCHINOV, Valentin. Marxismo e filosofia da linguagem. Problemas fundamentais do método sociológico na ciência da linguagem. $2^{\mathrm{a}}$ ed. Trad. Sheila Grillo e Ekaterina Vólkova Américo. São Paulo: Editora 34, 2018.

Artigo recebido em: ago. de 2020.

Aprovado e revisado em: nov. de 2020.

Publicado em: dez. de 2020.

Para citar este texto:

SILVA, Enrico de Castro Carvalho. A Perspectiva Bakhtiniana das Enunciações Emergentes na Ditadura Militar Brasileira: revisão de literatura. Entremeios [Revista de Estudos do Discurso, ISSN 2179-3514, on-line, www.entremeios.inf.br], Seção Estudos, Programa de Pós-Graduação em Ciências da Linguagem (PPGCL), Universidade do Vale do Sapucaí (UNIVÁS), Pouso Alegre (MG), vol. 22, p. 204-217, jul. - dez. 2020.

DOI: http://dx.doi.org/10.20337/ISSN2179-3514revistaENTREMEIOSvol22pagina204a217 